\title{
Perceptions and practice of epidural analgesia among women attending antenatal clinic in FETHA
}

This article was published in the following Dove Press journal:

International Journal of Women's Health

\author{
Paul O Ezeonu' \\ Okechukwu Bonaventure \\ Anozie' \\ Fidelis A Onu' \\ Chidi U Esike' \\ Johnbosco E Mamah' \\ Lucky O Lawani' \\ Robinson C Onoh' \\ Emmanuel Okechukwu \\ Ndukwe' \\ Richard Lawrence Ewah ${ }^{2}$ \\ Rita Onyinyechi Anozie ${ }^{3}$ \\ 'Department of Obstetrics and \\ Gynaecology, ${ }^{2}$ Department of \\ Anaesthesia, ${ }^{3}$ Department of \\ Radiology, Federal Teaching \\ Hospital Abakaliki, Abakaliki, \\ Ebonyi State, Nigeria
}

\begin{abstract}
Background: The pain of childbirth is arguably the most severe pain that most women will endure in their lifetime. Epidural analgesia is widely used as an effective method of pain relief in labor. It provides almost complete relief of pain if administered timely, and does not affect the progress of the first stage labor.

Objectives: The objective of this study was to determine the awareness and utilization of epidural analgesia in labor in pregnant women attending the antenatal clinic at Federal Teaching Hospital, Abakaliki (FETHA).
\end{abstract}

Methodology: This is a cross-sectional study involving 350 women attending the antenatal clinic between April 2016 and July 2016. A total of 335 questionnaires were correctly completed, and used for analysis.

Results: The average age and parity of the respondents were $27.6 \pm 8.2$ years and $2.4 \pm 1.8$, respectively. About $58.2 \%$ of respondents were civil servants, $98.5 \%$ were married, and $74.6 \%$ had a tertiary level of education. About $43.3 \%$ of the respondents are aware of the use of epidural analgesia in labor, but only $7.5 \%$ had used it; $95 \%$ of these were satisfied and desired to use it again. The reasons responsible for the poor uptake were desire to experience natural labor, cost, and fear of side effects. However, $70 \%$ of those who had not used it expressed the desire to use it.

Conclusion: Epidural analgesia is one of the most effective methods of pain relief in labor. However, the present study indicates that knowledge and practice of epidural analgesia among parturients are low. Efforts should be made to raise awareness, dispel misconceptions, and subsidize the cost of providing this invaluable care in modern day obstetrics.

Keywords: epidural, labor pain, practice, obstetric analgesia, perception

\section{Introduction}

The labor pain is probably the most severe pain that most women endure in their lifetime. ${ }^{1,2}$ Since pain relief in labor has always been surrounded by myths and controversies, providing effective and safe analgesia in labor have remained a perennial challenge. ${ }^{1}$ In some cultures, women are taught that labor pain is natural and the ability to accept and endure labor pain is a sign of womanhood. ${ }^{3}$ The American College of Obstetricians and Gynecologists (ACOG) rightly observed that labor is associated with severe pain for many women and that under no circumstance should a woman be allowed to bear pain which is amenable to safe intervention while under the care of a physician. ${ }^{4}$ It is therefore recommended that in the absence of any contraindication, pain relief should be provided in labor on maternal request. ${ }^{4,5}$ The National Institute for Clinical Excellence also recommends the education of pregnant women on the options and availability of effective analgesia in labor as a
Correspondence: Okechukwu

Bonaventure Anozie

Department of Obstetrics and

Gynaecology, Federal Teaching

Hospital Abakaliki, PMB 102, Abakaliki,

Ebonyi State, Nigeria 48000 I

Tel +2348035497498

Email okeyanoziey2k@yahoo.com 
means of ensuring that they receive optimal pain management during childbirth. ${ }^{6}$

Epidural analgesia is widely recognized and used as an effective method of pain relief in labour..$^{3-6}$ It provides almost complete labor pain relief (in $90 \%-95 \%$ of cases) if administered early and has been shown not to impede the progress of the first stage of labour. ${ }^{7}$ Epidural analgesia for labor and delivery involves the injection of a local anesthetic agent (lidocaine or bupivacaine) and/or an opioid (morphine or fentanyl) into the lumbar epidural space. The injected agent diffuses across the dura into the subarachnoid space where it acts primarily on the spinal nerve roots and to a lesser extent on the spinal cord and the paravertebral nerves to inhibit transmission of pain impulses. ${ }^{8-10}$

The use of epidural analgesia for relief of labor pain has increased globally in recent time. ${ }^{11,12}$ There is a wide disparity in its use among countries, and intra-country variation also exits. The practice of epidural analgesia is higher in highincome countries where it is considered as the mainstay of labor analgesia in 50\%-90\% of obstetric units. ${ }^{4,5,7,11,12}$ This is in sharp contrast to what is obtained in low-income countries with only between $1.3 \%$ and $12 \%$ of parturients benefitting from epidural analgesia. ${ }^{12,13}$

Neuraxial analgesia such as epidural analgesia is an effective method of pain control in labor. It provides effective relief of labor pain with little or no neonatal respiratory depressant effect. ${ }^{4,9,10,13}$ Despite these benefits, patient's refusal, bleeding dyscrasia (coagulopathy), infection at the site for needle insertion, raised intracranial pressure, poor skills on the part of the anesthetist, severe maternal hemorrhage, and maternal septicemia are contraindications to its use. ${ }^{9,14}$ It may be associated with some complications such as severe hypotension, prolonged second stage of labor, and increased risk of operative deliveries, urinary retention, postural puncture headache, epidural abscess, or meningitis. ${ }^{4,5,10}$

Despite the effectiveness of epidural analgesia in labor, it is not practiced in many obstetric units in Nigeria. ${ }^{14}$ Lack of the requisite skills for the administration of epidural analgesia, ignorance on the part of the parturient, and the extra cost for providing epidural analgesia in labor may all have contributed to low utilization of this effective method of labor pain relief, especially in low-resource settings. ${ }^{12,14}$

There are currently no local studies that have assessed patients' knowledge and the practice of epidural analgesia in labor in Abakaliki, Southeast Nigeria; hence, we set out to investigate the level of knowledge of our parturients on the subject and their labor pain management preference.

\section{Methodology Study area}

Ebonyi State is one of the five states in the South-East Geopolitical zone of Nigeria. It was created in 1996 from the largely rural areas of the preexisting Enugu and Abia states. It has three senatorial districts and 13 local government areas and an estimated population of 2.1 million people (2006 census). The Federal Teaching Hospital Abakaliki is located in the heart of the state capital. It receives referrals from peripheral hospitals within and outside the state. Patients who had their antenatal care with our facility were regarded as "booked" patients while patients who had their antenatal care elsewhere and/or were referred because of complications in pregnancy, labor, or puerperium without prior booking were regarded as "unbooked."

\section{Study population}

The participants were booked pregnant women attending the antenatal clinic of the Federal Teaching Hospital Abakaliki. Unbooked patients or patients in labor irrespective of their booking status were excluded from the study.

\section{Study design and sampling method}

This was a cross-sectional study involving 350 pregnant women who attended antenatal clinic between April 2016 and July 2016. Participants who gave informed consent to take part in the study were selected by simple random sampling technique. The sample size was 350. Sample size was calculated by using the formula $\mathrm{N}=\mathrm{Z}^{2} \mathrm{PQ} / \mathrm{D}^{2}$ (when population is $>10,000$ ); where $\mathrm{P}$ is the prevalence, $\mathrm{Q}$ is $1-\mathrm{P}$ (proportion of persons who have not used the procedure), $\mathrm{D}$ is allowable error margin which is $5 \%, \mathrm{Z}$ is a constant for standard normal deviation which is 1.96 at $95 \%$ CI. Taking P as $24.1 \%$, which is the proportion of respondents who had awareness of epidural analgesia in a previous study, ${ }^{15}$ this gave a sample size of 280. Applying an attrition rate of 20\% (56) gave a sample size of 336 which was approximated to 350 .

\section{Instrument}

The instrument for data collection was a self-administered pretested questionnaire that was subjected to a pilot survey involving 20 nonpregnant women randomly selected prior to the actual study.

\section{Data analysis}

The data were computed and analyzed with Epi info version 7 software (Center for Disease Control and Prevention, Chicago, IL, USA) and conclusions were drawn by means of descriptive statistics. 


\section{Ethical consideration}

Ethical clearance was obtained from the research and ethics committee of Federal Teaching Hospital Abakaliki (FETHA). Each participant signed an informed consent form prior to participation in the study, while the parents or legal guardians of those under the age of 18 years provided informed consent on their behalf.

\section{Results}

A total of 350 questionnaires were distributed, but only 335 were properly filled and suitable for analysis, giving a response rate of $95.7 \%$.

Table 1 shows the sociodemographic characteristics of the respondents. The mean age of the respondents was $27.6 \pm 8.2$ years. About two thirds $(64.60 \% ; 230 / 335)$ of the respondents were within the age range of 25-34 years, while $19.4 \%(65 / 335)$ were $>35$ years of age. The average parity of the respondents was $2.4 \pm 1$.8. Nulliparous women accounted for $10.40 \%$ of the respondents, while $47.80 \%$ accounted for a parity of 2-4. Majority of the respondents $58.20 \%$ (195/335) were civil servants, while 13.40 (45/335) were housewives.

Table I Sociodemographic characteristics, occupation, and parity $(\mathrm{N}=335)$

\begin{tabular}{|c|c|c|}
\hline Variables & Frequency & Percentage \\
\hline \multicolumn{3}{|l|}{ Age (years) } \\
\hline $15-19$ & 10 & 3.00 \\
\hline $20-24$ & 30 & 9.00 \\
\hline $25-29$ & 115 & 34.30 \\
\hline $30-34$ & 115 & 34.30 \\
\hline$>35$ & 65 & 19.40 \\
\hline \multicolumn{3}{|l|}{ Occupation } \\
\hline Civil servant & 195 & 58.20 \\
\hline Trader & 35 & 10.40 \\
\hline Farmer & 10 & 3.00 \\
\hline Housewife & 45 & 13.40 \\
\hline Others & 50 & 15.00 \\
\hline \multicolumn{3}{|c|}{ Highest level of education } \\
\hline Primary & 5 & 1.50 \\
\hline Secondary & 80 & 23.90 \\
\hline Tertiary & 250 & 74.60 \\
\hline \multicolumn{3}{|l|}{ Tribe } \\
\hline Igbo & 320 & 95.50 \\
\hline Yoruba & 10 & 3.00 \\
\hline Hausa & 0 & 0 \\
\hline Others & 5 & 1.50 \\
\hline \multicolumn{3}{|c|}{ Marital status } \\
\hline Single & 5 & 1.50 \\
\hline Married & 330 & 98.50 \\
\hline \multicolumn{3}{|l|}{ Parity } \\
\hline None & 35 & 10.40 \\
\hline I & 105 & 31.30 \\
\hline $2-4$ & 160 & 47.80 \\
\hline$>5$ & 35 & 10.40 \\
\hline
\end{tabular}

Table 2 Experience of labor pain $(n=335)$

\begin{tabular}{lll}
\hline Variable & Frequency $(\mathbf{n})$ & Percentage (\%) \\
\hline Experience of labor pain & & \\
Yes & 300 & 89.60 \\
No & 35 & 10.40 \\
Need for labor pain relief & & \\
Yes & 270 & 80.60 \\
No & 15 & 04.50 \\
Indifferent & 50 & 14.90 \\
Total & 335 & 100 \\
\hline
\end{tabular}

A good number of the respondents 74.60\% (250/335) had tertiary education, $23.90 \%(80 / 335)$ had secondary education, and only $1.50 \%(5 / 335)$ had only primary education. Majority of the study population $98.50 \%$ (330/335) were married, while $1.50 \%(5 / 335)$ was unmarried.

Regarding the respondents' knowledge of labor pains, Table 2 indicates that $89.60 \%$ (300) had previously experienced labor, while $10.40 \%$ (35) was nulliparous. Of the total number of respondents, $80.60 \%$ (270) would opt for pain relief in labor, while $14.90 \%$ (50) were indifferent, and the remainder objected to its use.

Regarding their knowledge of methods of pain relief in labor (Table 3), many of the respondents $65.70 \%$ (220) were aware of at least a pharmacological method of pain relief. The commonest method they had knowledge of was pentazocine injection, while a little over two fifths (43.30\%) were knowledgeable about epidural analgesia. One hundred and fifteen of the respondents had no knowledge of any effective method of labor pain relief.

Table 4 shows the level of awareness of epidural analgesia. Less than half of the respondents $(43.30 \%$; 145/335) were aware of epidural analgesia for labor pain, while $52.20 \%$ were not aware of it, and the remainder (4.5\%) was not sure of its role. Only $29 \%$ of those who had knowledge of epidural analgesia were aware that it was provided in FETHA. Regarding awareness on the mode of administration of epidural analgesia, only $35.90 \%$ of the respondents had correct knowledge, while $64.10 \%$ of them had no idea. The effectiveness of epidural analgesia for relief of labor pain was answered correctly by $23.90 \%$ of the respondents.

Table 3 Knowledge of methods of pain relief in labor $(n=335)$

\begin{tabular}{lll}
\hline Methods & Frequency (n) & Percentage (\%) \\
\hline Pethidine injection & 25 & 7.50 \\
Pentazocine injection & 220 & 65.70 \\
Tramadol injection & 200 & 60.00 \\
Epidural analgesia & 145 & 43.30 \\
Inhalational entonox & 15 & 4.50 \\
None & II5 & 34.30 \\
\hline
\end{tabular}


Table 4 Knowledge of epidural analgesia

\begin{tabular}{|c|c|c|}
\hline Variables & Frequency & Percentage \\
\hline \multicolumn{3}{|c|}{ Aware of epidural analgesia for labor pain } \\
\hline Yes & 145 & 43.30 \\
\hline No & 175 & 52.20 \\
\hline I am not sure & 15 & 4.50 \\
\hline \multicolumn{3}{|c|}{ Are you aware it is provided in FETHA? } \\
\hline Yes & 42 & 29.00 \\
\hline No & 71 & 48.90 \\
\hline I am not sure & 32 & 22.10 \\
\hline \multicolumn{3}{|c|}{ Epidural is the administration of a local anesthetic through } \\
\hline \multicolumn{3}{|c|}{ a catheter into the epidural space of the spine } \\
\hline Yes & 52 & 35.90 \\
\hline Do not know & 93 & 64.10 \\
\hline \multicolumn{3}{|c|}{ Epidural analgesia is one of the best forms of pain relief in labor } \\
\hline Yes & 35 & 23.90 \\
\hline Do not know & 110 & 76.10 \\
\hline \multicolumn{3}{|c|}{ Epidural analgesia is administered by? } \\
\hline A doctor & 37 & 25.37 \\
\hline A nurse & 15 & 10.45 \\
\hline Any health worker & 19 & 13.43 \\
\hline I do not know & 74 & 50.75 \\
\hline
\end{tabular}

Table 5 shows the source of information of epidural analgesia in labor. Majority of the respondents got their information regarding the use of epidural analgesia for pain relief in labor from doctors (79.30\%), nurses (55.20\%), and Internet sources $(41.40 \%)$. Antenatal classes held in the antenatal clinic (group sessions) was the source of information for $32.40 \%$ of the respondents.

Majority (72.41\%) of the respondents who were aware of epidural analgesia had no knowledge of the complications associated with its use, but over a quarter $(27.60 \%)$ had some knowledge of possible complications (Table 6).

Table 7 shows the intention to use epidural analgesia, indicating that only $7.50 \%(25 / 335)$ of the respondents had used epidural analgesia in labor. However, $50.70 \%$ of the respondents agreed that epidural analgesia should be made available in labor, while others were either indifferent (28.40\%) or did not support its use (20.90\%). Most respondents had not received adequate information on the use and benefits of epidural analgesia in labor (71.60\%).

Table 8 indicates that all but one respondent were satisfied with the outcome of labor managed with epidural

Table 5 Source of information $(n=\mid 45)$

\begin{tabular}{lll}
\hline Source of information & Frequency & Percentage \\
\hline Doctor & 115 & 79.30 \\
Nurse & 80 & 55.20 \\
Antenatal classes & 47 & 32.40 \\
Family and friends & 35 & 24.14 \\
Media/Internet & 60 & 41.40 \\
\hline
\end{tabular}

Table 6 Knowledge of complications of epidural analgesia in labor $(n=145)$

\begin{tabular}{lll}
\hline Complication & Frequency & Percentage \\
\hline Back pain & 25 & 17.20 \\
Headache & 35 & 24.14 \\
Increased interventions in labor & 45 & 31.03 \\
Increase risk of cesarean section & 15 & 10.34 \\
Low blood pressure & 15 & 10.34 \\
Prolongation of second-stage labor & 10 & 6.90 \\
Effect on the unborn baby & 40 & 27.59 \\
None & 105 & 72.41 \\
\hline
\end{tabular}

analgesia, with $92 \%$ likely to request for it again in future. One respondent was indifferent about repeat use. About $96 \%$ of the respondents said they would recommend it to other parturients.

Among those who had not used epidural analgesia in labor (Table 9), 70\% (217) desired to use it when in labor, $16.13 \%$ would not want it, while $13.87 \%$ were not sure of their decision on its future use. The reasons for not wanting to use it were mainly due to the cost of the service (70\%), desire to experience natural labor (64.52\%), and fear of side effects $(48.40 \%)$, and $32.30 \%$ had no reason.

\section{Discussion}

Pain management in labor has undergone various revolutions since 1847 when Simpson observed that chloroform could help relieve the pain women felt during labour. ${ }^{16}$ Despite remarkable advancement in labor analgesia, acceptability and applicability of epidural analgesia in labor has not received enough coverage in our setting. ${ }^{12-14,17-19}$

Table 7 Attitude and practice of women toward epidural analgesia in labor $(n=335)$

\begin{tabular}{|c|c|c|}
\hline Variables & Frequency & Percentage \\
\hline \multicolumn{3}{|c|}{ Have you used epidural analgesia in labor? } \\
\hline Yes & 25 & 7.50 \\
\hline No & 310 & 92.50 \\
\hline \multicolumn{3}{|c|}{ Epidural analgesia should be made available to all women } \\
\hline \multicolumn{3}{|c|}{ in labor if they desire its use } \\
\hline Yes & 170 & 50.70 \\
\hline No & 70 & 20.90 \\
\hline I am indifferent & 95 & 28.40 \\
\hline \multicolumn{3}{|c|}{ Have you received adequate information on various forms } \\
\hline \multicolumn{3}{|c|}{ of pain relief in labor including epidural analgesia? } \\
\hline Yes & 70 & 20.90 \\
\hline No & 240 & 71.60 \\
\hline I am not interested & 25 & 7.50 \\
\hline \multicolumn{3}{|c|}{ Would you like to know more about forms of pain relief } \\
\hline \multicolumn{3}{|c|}{ in labor including epidural analgesia? } \\
\hline Yes & 295 & 88.00 \\
\hline No & 30 & 09.00 \\
\hline I am indifferent & 10 & 03.00 \\
\hline
\end{tabular}


Table 8 Those who have used epidural analgesia in labor $(\mathrm{N}=25)$

\begin{tabular}{lcc}
\hline Variables & Frequency & Percentage \\
\hline What was your experience & from using epidural & analgesia in labor? \\
Satisfied & 24 & 96.00 \\
I was not satisfied & $\mathrm{I}$ & 4.00 \\
Would you like to use it again? & \\
Yes & 23 & 92.00 \\
No & $\mathrm{I}$ & 4.00 \\
I am not sure & $\mathrm{I}$ & 4.00 \\
Willingness to recommend epidural analgesia to another person \\
Yes & 24 & 96.00 \\
No & $\mathrm{I}$ & 4.00 \\
\hline
\end{tabular}

The current study shows that $74.60 \%$ of the respondents had tertiary-level education. However, its relationship with the level of awareness and practice of epidural analgesia was not determined in this study, but there are conflicting findings from similar studies elsewhere. A study in Lagos found a significant association between the educational status of the respondents and their knowledge of obstetric analgesia ${ }^{18}$ while similar studies in Ibadan and Maiduguri did not find any positive correlation. ${ }^{17,19}$

Our study showed that $80.60 \%$ of the respondents desired pain relief in labor despite almost four fifths (79\%) of the respondents reporting no health education on labor analgesia by care providers. However, $88 \%$ expressed the desire for enlightenment regarding obstetric analgesia. It is therefore important for health workers to educate and offer women counseling on options of pain relief in labor, since the present study indicates that parturients did not have sufficient knowledge on the risks and benefits of labor analgesia to make an informed choice. The high demand for pain relief in labor by the respondents in this study was similar to the report by Iliyasu et al in $\mathrm{Kano}^{20}$ and Audu et al in Maiduguri ${ }^{19}$ but Kuti and Faponle in Southwest Nigeria reported that majority of the respondents were averse to pain relief in labor

Table 9 Those who have not used epidural analgesia in labor $(n=3 \mid 0)$

\begin{tabular}{lcc}
\hline Variables & Frequency & Percentage \\
\hline Would you like to use epidural analgesia in labor? & \\
Yes & 217 & 70.00 \\
No & 50 & 16.13 \\
I am not sure & 43 & 13.87 \\
Reason for rejecting epidural analgesia (n=93) & \\
Cultural reason & 5 & 5.40 \\
Fear of side effects & 45 & 48.40 \\
I want natural labor without pain relief & 60 & 64.52 \\
I have no reason & 30 & 32.30 \\
Expensive & 70 & 75.30 \\
\hline
\end{tabular}

because labor pain was perceived as divine and should not be interfered with. ${ }^{21}$

Experience has shown that even among parturients who declined pain relief prior to the onset of labor, some may request it at the height of labor pain; this is usually the period of transiting from the first to the second stage of labor, this is a period of intense uterine contraction between 7 and $10 \mathrm{~cm}$ of cervical dilatation. At such times, women may do more with emotional support from health workers or relatives and not necessarily providing pharmacological pain relief. 6,19

This study found that more than half of the respondents knew at least one pharmacological method of pain relief in labor with pentazocine injection being the most common $(65.70 \%)$. In the present study, pentazocine was the commonest analgesia used for labor pain relief and may account for the level of awareness reported. The finding on utilization of epidural analgesia (43.30\%) is higher than the $10 \%$ recorded in Ibadan $^{17}$ and $12 \%$ recorded in Benin ${ }^{12}$ but similar to $47 \%$ and $42 \%$ reported in Hong Kong ${ }^{22}$ and Riyadh, ${ }^{23}$ respectively. However, it is less than the $76 \%$ in $\mathrm{Karachi}^{7}$ and $62.5 \%$ reported in Chennai. ${ }^{20}$ One common finding from the available literature is the fact that majority of the women who knew about epidural analgesia for the relief of labor pain were educated. . $^{722-24}$

Even though respondents in this study were aware of epidural analgesia in labor, this knowledge was more of surface value. For instance, only $29 \%$ of respondents were aware that it was being provided in FETHA, 35.90\% were aware of the mode of its administration, $23.90 \%$ knew its effectiveness, and a significant proportion had no knowledge of its complications. This finding suggests that healthcare providers have to make more efforts in educating women on the options of pain relief in labor with the emphasis that labor pain was physiologic and transient and may not require an active intervention other than provision of support and adequate information on the physiology of labor. This study found that almost two thirds of the respondents $(64.52 \%)$ desired natural labor. They should be encouraged to do so provided they are adequately informed of the available options.

The sources of information on epidural analgesia for pain relief in labor among respondents were from doctors $(79.30 \%)$, nurses $(55.20 \%)$, and Internet $(41.40 \%)$. This is different from the findings in Karachi where doctors were the source of information among $40 \%$ of the respondents and the Internet accounted only $1 \%$. Another study by Pattee et al in Ontario ${ }^{25}$ showed that information about epidural analgesia was mainly from anesthetists and antenatal classes. 
This emphasizes the importance of routine education on labor analgesia including the option of epidural analgesia.

Similarly, knowledge of complications of epidural analgesia was low as almost three-quarters (72.41\%) of the respondents had no idea of possible complications. Majority of the responses on complications were subjective and wrong. Those who had the knowledge of the possible complications cited increased interventions in labor $(21.3 \%)$, effect on the unborn baby (27.59\%), and headache (17.20\%) just to mention a few. These findings were similar to those reported by Pattee et $\mathrm{al}^{25}$ and Barakzai et al. ${ }^{24}$

Although 7.5\% (25) of the respondents had used epidural analgesia in labor, all but one expressed satisfaction and would desire it again in the current pregnancy. This enthusiasm was similar to that found in other similar studies. ${ }^{26-28}$ Even among physicians with very high knowledge about the effectiveness of epidural analgesia, its practice leaves much to be desired. ${ }^{2,28,29}$ Some women who reported not to have used epidural analgesia adduce high cost as a reason, indeed provision of epidural analgesia costs about four times more than the more commonly used pentazocine in the maternity unit of the study center. Therefore, subsidizing cost or the provision of free epidural services under the National Health Insurance scheme may improve uptake.

Interestingly, this study found that $70 \%$ of the respondents would like to utilize epidural analgesia in the current pregnancy if provided with adequate information. The fact that the respondents reported lack of sufficient information to make an informed choice on labor analgesia is an important finding from this study. Therefore, healthcare providers need to provide sufficient information on the options of pain relief in labor including the benefit of companionship in minimizing analgesic interventions during labor.

In conclusion, this study has revealed a large lacuna in the knowledge of pain relief in labor and of epidural analgesia in labor among pregnant women in Abakaliki. Since women desire to know more about this subject, efforts should be made to raise awareness by providing health education, dispelling misconceptions, and subsidizing the cost of providing this service in labor.

\section{Disclosure}

The authors report no conflicts of interest in this work.

\section{References}

1. Reena KH, Afzal M, Mishra AK, Paul A. Labour epidural analgesia: past, present and future. Indian J Pain. 2014;28(2):71-81.
2. Lawani LO, Eze JN, Anozie OB, Iyoke CA, Ekem NN. Obstetric analgesia for vaginal birth in contemporary obstetrics: a survey of the practice of obstetricians in Nigeria. BMC Pregnancy Childbirth. 2014;14(140):1-6.

3. Obuna JA, Umeora OU. Perception of labour pain and utilization of obstetric analgesia by Igbo women of Southeast Nigeria. J Obstet Anaesth Crit Care. 2014;4(1):18-22.

4. ACOG. Analgesia and caesarean delivery rates. Committee Opinion Number 339; June 2006:1-2.

5. ACOG. Pain relief during labour. Committee Opinion Number 295; July 2004:1.

6. NICE. Intrapartum care for healthy women and babies. Clinical Guidelines (CG 190); December 2014:1-103.

7. Minhas MR, Kamal R, Afshan G, Raheel H. Knowledge, attitude and practice of Parturients regarding epidural analgesia for labour in a University Hospital in Karachi. J Pak Med Assoc. 2005;55(63):123-125.

8. Hawkins JL. Epidural analgesia for labour and delivery. $N$ Engl J Med. 2010;362(16):1503-1510.

9. Women and Newborn Health Services, King Edward Memorial Hospital. Epidural analgesia in labour. Clinical guidelines relevant to anaesthetists. Ref 443:1-7. Available from http:// www. kemh.health. wa.gov.au/development/manuals/O\&G_guidelines/sectione/4/e4.1.pdf. Accessed December 1, 2017.

10. Anim-Somuah M, Smyth RM, Jones L. Epidural versus non-epidural or no analgesia in labour. Cochrane Database Syst Rev. 2011;12: CD000331.

11. Kothari D, Bindal J. Impact of obstetric analgesia (regional vs parenteral) on progress and outcome of labour: a review. J Rom Anest Terap Int. 2011;18(1):34-40.

12. Amadasun FE, Aziken ME. Knowledge and attitude of pregnant women to epidural analgesia in labour. Ann Biomed Sci. 2008;7(1-2): $156-162$.

13. Imarengiaye CO, Olagbuji BN, Ezeanochie MC, Akhideme II. Clinical correlates of women requesting labour epidural analgesia in a tertiary hospital in Nigeria. Niger PG Med J. 2013;20(3):214-217.

14. Oladokun A, Olayinka E, Imran OM, Olajide F, Joshua A, Adedokun B. Awareness and desirability of labour epidural analgesia: a survey of Nigerian women. Int J Obstet Anesth. 2009;18(1):38-42.

15. Okojie NQ, Isah EC. Perception of epidural analgesia for labour among pregnant women in a Nigerian tertiary hospital setting. J West Afr Coll Surg. 2014;4(4):142-162.

16. Mugambe JM, Hiemstra LA, Nel M, Steinberg WJ. Knowledge of and attitude towards pain relief during labour of women attending the antenantal clinic of Cecilia Makiwane Hospital, South Africa. SA Fam Pract. 2007;49(4):16-20.

17. Olayemi O, Aimakhu CO, Udoh ES. Attitudes of patients to obstetric analgesia at the University College Hospital Ibadan, Nigeria. J Obstet Gynecol. 2003;23(1):38-40.

18. Okeke CI, Merah NA, Cole SU, Osiboigun A. Knowledge and perception of obstetric analgesia among prospective parturients at Lagos University Teaching Hospital. Niger Postgrad Med J. 2005;12: 258-261.

19. Audu B, Usman Y, Bukar M, Aliyu E, Abdullahi H, Kyari O. Desire for pain relief in labour in Northern Nigeria. J Public Health Epidemiol. 2009;1(2):53-57.

20. Iliyasu Z, Galadanci H, Abubakar I, Isah H, Aliyu A. Desire for obstetric analgesia among women in Northern Nigeria. Trop J Obstet Gynaecol. 2012;29(2):59-61.

21. Kuti O, Faponle AF. Perception of labour pain among the Yoruba ethnic group in Nigeria. J Obstet Gynaecol. 2006;26:332-334.

22. William WK. A questionnaire survey on patients attitudes towards epidural analgesia in labour. Hong Kong Med J. 2007;13(3):208-215.

23. Mohamed HF, Jamila A, Almobaya N, Aldosary M, Alnajay H. Women's awareness and attitude toward epidural analgesia. J Bio Agric Health. 2013;3(6):46-52. 
24. Barakzai A, Gulfareen H, Yousuf F, Haider A, Muhammad N. Awareness of women regarding analgesia during labour. J Ayub Med Coll Abbottabad. 2010;22(1):73-75.

25. Pattee C, Ballantyne M, Milne B. Epidural analgesia for labour and delivery: informed consent issues. Can J Anaesth. 1997;44(9):918-923.

26. Loubert C, Hinova A, Fernando R. Update on modern neuraxial analgesia in labour: a review of the literature of the last 5 years. Anaesthesia. 2011;66:191-212.

27. James JN, Prakash KS, Ponnia M. Awareness and attitudes towards labour pain and labour pain relief of urban women attending a private antenatal clinic in Chennai, India. Indian J Anaesth. 2012;56(2): 195-198.
28. Vandendriesen NM, Lim W, Paech MJ. Obstetricians knowledge and attitudes toward epidural analgesia in labour. Anaesth Intensive Care. 1998;26(5):563-567.

29. Taneja B, Nath K, Dua CK. Clinical audit on the existing attitudes and knowledge of obstetricians regarding labour analgesia. Indian $J$ Anaesth. 2004;48(3):185-188.
International Journal of Women's Health

\section{Publish your work in this journal}

The International Journal of Women's Health is an international, peerreviewed open-access journal publishing original research, reports, editorials, reviews and commentaries on all aspects of women's healthcare including gynecology, obstetrics, and breast cancer. The manuscript management system is completely online and includes

\section{Dovepress}

a very quick and fair peer-review system, which is all easy to use. Visit http://www.dovepress.com/testimonials.php to read real quotes from published authors.

Submit your manuscript here: http://www.dovepress.com/international-journal-of-womens-health-journal 